\title{
Policy Effort Analysis on China's New Rural Cooperative Medical System
}

\author{
Sheng-Ji LI ${ }^{1, a,{ }^{*}, \text { Man-Xue CHEN }}{ }^{1, b}$, Kang-Yin LU ${ }^{1, c}$ \\ ${ }^{1}$ School of Business, Northeast Normal University, P. R. China, 130117

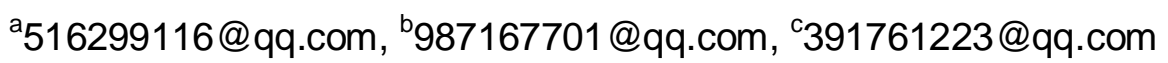 \\ ${ }^{*}$ Corresponding author
}

Keywords: Rural health level, Effect of new rural cooperative medical system, Health, Income.

\begin{abstract}
From the perspective of rural health level, we analyze the policy effect of China's New Rural Cooperative Medical System on rural areas and inter-province in the method of quantitative analysis. The results show that from the overall level of the countryside, the establishment of the New Rural Cooperative Medical System play a positive role in safeguarding the health of farmers, improve the income situation of farmers and improve farmers' ability of resist risks. However, the effect of the New Rural Cooperative Medical System in different province on health and income levels of farmers is different. Compared to other provinces, Shandong and Liaoning provinces' effect of the implementation is relatively better.
\end{abstract}

\section{Introduction}

In 2003, the Chinese State Council issued "new rural cooperative medical system view on the establishment " stress that guiding and organizing farmers to build new rural cooperative medical insurance system to protect farmers illness based under the guidance of the government. From 2003 to 2014, the new rural cooperative medical care system has experienced from the pilot run stage to the comprehensive promotion stage and it has covered most Chinese farmers.

Chinese scholars had made many researches on policy effect of New Rural Cooperative Medical System. About the effect on policies before and after implement this system, Shanlian Hu (2004) hold that although the implementation of the new rural cooperative policy is basically running smoothly, it could not prevent the problem of peasants "poverty due to illness" and lag of government funding[1]. Jiangang Zheng (2008) believes that the implementation of the new rural cooperative medical service needs of the famers had changed. Attendance rate declined in two weeks, but the hospitalization rate rise, the rate need to be hospitalized and not in the hospital showing a downward trend on the analysis of the effect of different mode of new farmers and policy[2]. Mengtao Gao(2005) studies three pilot counties in Yunnan and find that personal accounts did not increase farmer participation rate instead of weakening its anti-risk capabilities. An appropriate increase on poor farmers in the proportion of medical expenses compensation could be benefit to improve poor farmers and reduce inequality of medical services' system utilization[3]. At different levels of economic development, medical system analysis on policy effects of the new rural cooperative aspect, Ninghe Zhou and Xianghong Zhou (2009) considered the new agricultural policy implementation in the less developed areas alleviate the problem of farmers' expensive. However, due to the low level of economic, it is difficult to form higher security capabilities. The disadvantages of it in underdeveloped areas exposed to improve and refine[4].

Previous research literature on the implementation effect of New Rural Cooperative Medical System indicates that the proposed of this system alleviate farmers' health inequalities to some extent. With the development of this system, dependent on the health status of income phenomenon 
are diluted gradually. This paper in the perspective of rural health to investigate whether the policy has corresponding policy effects on the health and income of farmers.

\section{Research Design}

\section{Data Sources and Descriptive Statistics}

Table 1. Sample distribution

\begin{tabular}{|c|c|c|c|c|}
\hline Province/Area & Sample & Percentage(\%) & Man & Percentage(\%) \\
\hline Liaoning & 382 & 11.0 & 231 & 60.5 \\
\hline Jiangsu & 476 & 14.0 & 256 & 53.8 \\
\hline Shandong & 368 & 11.0 & 202 & 54.9 \\
\hline Heilongjiang & 352 & 10.0 & 203 & 57.7 \\
\hline Henan & 317 & 9.0 & 191 & 60.3 \\
\hline Hubei & 342 & 10.0 & 178 & 52.0 \\
\hline Hunan & 388 & 11.0 & 232 & 59.8 \\
\hline Guizhou & 400 & 12.0 & 229 & 57.3 \\
\hline Guangxi & 420 & 12.0 & 219 & 52.1 \\
\hline Countryside & 2040 & 59.0 & 1172 & 57.5 \\
\hline
\end{tabular}

Data sources of this paper comes from Chinese Health and Nutrition Survey(CHNS), CHNS's(2006) sample data which surveys the adults over 18 years old includes 9789 person. Of which city sample is 3361 and rural sample is 6428. The effective sample size selected of this paper is 2040. From the total sample randomly selected, people join the New Rural Cooperative Medical cover $55.3 \%$.

After excluding some observations which miss health, income, gender and other important variables, the final sample size is 2040 people, including 1172 males, and 868 females. The sample distribution is shown in Table 1. 
Table 2. Variable definition

\begin{tabular}{|c|c|c|}
\hline Variable & Variable logo & Definition \\
\hline SEH & Self-rated health & $\begin{array}{c}\text { Very good }=1, \text { Good }=2, \\
\text { General }=3, \text { Poor }=4\end{array}$ \\
\hline Inc & $\begin{array}{l}\text { Personal annual } \\
\text { income } \\
\text { (logarithmic) }\end{array}$ & $\begin{array}{l}\text { Including family fruit and vegetable garden income, household } \\
\text { agricultural income, family farming income, family fishing and } \\
\text { income, household small handicraft and small business income, } \\
\text { income from a second job, and other cash income, other } \\
\text { non-cash income }\end{array}$ \\
\hline Edu & Education & $\begin{array}{l}\text { Including primary school, middle school, high school, middle } \\
\text { school and vocational technical school graduate, college or } \\
\text { university graduate, master's and above }\end{array}$ \\
\hline Gender & Gender & Man $=1$, Woman $=0$ \\
\hline Age & Age & $18 \sim 78$ \\
\hline $\mathbf{M}$ & $\begin{array}{l}\text { New rural } \\
\text { cooperative } \\
\text { medical system }\end{array}$ & $\mathrm{Yes}=1, \mathrm{No}=0$ \\
\hline
\end{tabular}

\section{Econometric Model}

The theoretical model of this paper comes from Grossman health model theory(1972). We select age and gender as individual characteristics, select income, education and whether join new rural cooperative medical as independent variables, and select self-rated health as dependent variable. Mathematical equation is below:

$$
\mathrm{SHE}=\beta_{0}+\beta_{1} \mathrm{Inc}+\beta_{2} \mathrm{Edu}+\beta_{3} \text { Gender }+\beta_{4} \mathrm{Age}+\beta_{5} \mathrm{M}+\varepsilon
$$

Self-rated health of CHNS is divided into four grades. Since the dependent variable is not continuous data but discrete data, we use Tobit discrete dependent variable regression model for maximum likelihood estimation (MLE).

\section{Quantitative Analysis}

The Direct Influence of the New Rural Cooperative Medical System

Table 3. Overall sample regression

\begin{tabular}{|c|c|c|c|c|c|}
\hline Variable & Inc & Age & Gendre & Edu & M \\
\hline Coefficient & $\mathbf{- 0 . 0 9 3} * *$ & $\mathbf{0 . 0 1 2} * *$ & $\mathbf{- 0 . 0 7 2} *$ & $\mathbf{- 0 . 0 4 3} * *$ & $\mathbf{- 0 . 0 8 7} * *$ \\
\hline Std. Error & $(0.017)$ & $(0.001)$ & $(0.038)$ & $(0.015)$ & $(0.038)$ \\
\hline z-Statistic & -5.481 & 7.793 & -1.870 & -2.785 & -2.280 \\
\hline
\end{tabular}


Note: The coefficients of the variables in the table, the values in brackets standard deviation, "**" indicates a significant level of under 0.05 , "*" indicates a significant level of under 0.1.(The same below)

Rural overall sample regression results show that Log likelihood is -1920.36, Avg.log likelihood is -1.179 , which indicate that the overall sample model fit better in rural areas.

The regression results, according to Table 3, show that age had a significant negative effect on health, people's health being worse as the growth of the age. Education has significant positive impact on the health of farmers. The higher education, the better is farmers' health. Farmers with high level of education take their own health more serious. When the government put forward New Rural Cooperative Medical System, they participate in it actively. There is no denying this system is a basic medical security system, which benefit to people's health. That is to say, farmers taking part in the system enjoy primary medical service and health care. Therefore, from the overall level of rural, farmers' health participating in the system is better than others. Income has also a significant positive effect on health. With the increase of income, farmers' health presents a better trend due to the high earners than low-income people have more health resources. So finance investing heavily in rural finance medical and health services makes this system improving the income of farmers and meets farmers' demand for medical services. At the same time, the medical expenses compensation mechanism of this system relieves farmers from poor caused by illness.

\section{Effect of Provincial Differences}

The regression results in Table 4show that with age has significant negative impact on health except of Guangxi province. Impact of education on health has provincial difference. Education level has greater impact on health in Henan, while less in Liaoning.

Impact of income on health has provincial difference. Expect Shandong, Hunan, Hubei and Guizhou, income of the other five provinces has significant positive effect on health. That is because in Jiangsu, New Rural Cooperative Medical System is Planning Model of Hospitalization, which only reimburses inpatient medical expenses regardless of outpatient medical expenses. Farmers participating are persons getting serious ill. In Liaoning, it is Family Account Mode, farmers ensure family member's medical expenses with family accounts. Individual contribution and government subsidies for farmers are into the family account as medical expenses. This system in Shandong and Guizhou is hospitalization Plus Outpatient Co-ordination Mode. Farmers no matter getting what ill can be protected. Its fund and compensation mechanisms improve the income level of farmers, reducing farmers' health dependence on income. 
Table 4. Provincial sample regression

\begin{tabular}{|c|c|c|c|c|c|}
\hline Province & Inc & Age & Gendre & Edu & $\mathbf{M}$ \\
\hline \multirow{2}{*}{ Liaoning } & $-0.131 * *$ & $0.023 * *$ & $-0.079 * *$ & $-0.108 * *$ & $-0.269 * *$ \\
\hline & $(0.044)$ & $(0.004)$ & $(0.101)$ & $(0.033)$ & (0.099) \\
\hline \multirow{2}{*}{ Heilongjiang } & $-0.138 * *$ & $0.017 * *$ & -0.049 & -0.009 & 0.112 \\
\hline & $(0.061)$ & $(0.006)$ & $(0.134)$ & $(0.051)$ & $(0.126)$ \\
\hline \multirow{2}{*}{ Jiangsu } & $-0.123 * *$ & $0.009 * *$ & -0.121 & 0.006 & $0.247 * *$ \\
\hline & $(0.053)$ & $(0.004)$ & $(0.103)$ & $(0.044)$ & $(0.115)$ \\
\hline \multirow{2}{*}{ Shandong } & -0.058 & $0.027 * *$ & $-0.421 * *$ & 0.004 & $-0.218^{*}$ \\
\hline & $(0.048)$ & $(0.004)$ & $(0.099)$ & $(0.046)$ & $(0.132)$ \\
\hline \multirow{2}{*}{ Henan } & $-0.089 *$ & $0.022 * *$ & 0.095 & $-0.147 * *$ & -0.208 \\
\hline & $(0.050)$ & $(0.005)$ & $(0.154)$ & $(0.071)$ & $(0.137)$ \\
\hline \multirow{2}{*}{ Hubei } & 0.116 & $0.034 * *$ & 0.097 & $-0.136 * *$ & -0.220 \\
\hline & $(0.072)$ & $(0.007)$ & $(0.144)$ & $(0.067)$ & $(0.156)$ \\
\hline \multirow{2}{*}{ Hunan } & -0.073 & $0.012 * *$ & 0.04 & -0.042 & -0.031 \\
\hline & $(0.046)$ & $(0.004)$ & $(0.112)$ & $(0.043)$ & $(0.111)$ \\
\hline \multirow{2}{*}{ Guangxi } & $-0.079 * *$ & -0.0002 & -0.004 & $-0.181 * *$ & 0.022 \\
\hline & $(0.034)$ & $(0.003)$ & $(0.091)$ & $(0.038)$ & $(0.089)$ \\
\hline \multirow{2}{*}{ Guizhou } & -0.088 & $0.013 * *$ & -0.144 & 0.081 & $-0.222 *$ \\
\hline & $(0.067)$ & $(0.004)$ & $(0.131)$ & $(0.049)$ & $(0.123)$ \\
\hline
\end{tabular}

Family Account mode improves the income of farmers in Heilongiiang and Henan. The compensation mechanism in the New Rural Cooperative Medical System improves farmers' income. So income has a significant positive impact on health, but the poor awareness of participating in this system makes the effect not significant. As Shandong and Guizhou, Guangxi has the same mode. It improves income levels.

In the whole, the establishment of this system plays a positive role in protection of the farmers' health and improves the income situation of farmers. But in different province, the impact shows differences.

\section{Conclusions}

In this paper, using Tobit discrete dependent variable regression model to analyze the impact of China's new Rural Cooperative Medical System on income and health of rural areas and different province.

The conclusions are that between income and health in China's rural has a significant positive correlation. Age on health has a significant negative correlation. In the interprovincial, part of income on health has a positive correlation, while age has a negative correlation to health. New Rural Cooperative Medical System had improved the income situation of farmers to enable farmers to improve anti-risk capability. 
Through quantitative analysis method confirm that the New Rural Cooperative Medical System has some positive effect on the health and income of farmers indeed. For this make relevant recommendations:

First, government needs to strengthen health education for rural residents. The government should increase the farmers' health education, such as health care knowledge education. Enable farmers realize the importance of a healthy through public education to develop healthy good health habits.

Second, government should increase investment in rural medical and health undertakings financial investment. Government should increase financial investment to improve the poor sanitation of facilities rural health care providers and health service personnel. Administrative means should be used to allocate too much health and health service personnel resources in the city to rural health service institutions. And change the health care resources and personnel gap between urban and rural areas.

Third, improve the compensation mechanism of this system, the compensation ratio and benefit levels. The compensation medical expenses of this system cushion the impact on the health of farmers the price of medical services. Therefore, the government should simplify New Rural Cooperative Medical System reimbursement process to improve its reimbursement and reduce undulating lines. And improve the cap line according to local circumstances to make more farmers could get the policy concessions.

\section{References}

[1] Shanlian Hu. The Financing Status of New Rural Medical Care System[J], Chinese Health Economics, 2004(9).

[2] Jiangang Zheng. The Continuous Tracking for Five Years of the New Rural Medical Service Demand and Utilization Effect[J], Chinese Rural Health Service Administration,2008(2).

[3] Mengtao Gao. The Effect of New Rural Medical Care System in Demand[J], Chinese Health Economics,2005(5).

[4] Ninghe Zhou,Xianghong Zhou. New Rural Medical Care System Effect and Policy Suggestions of Underdeveloped Regions[J], Chinese Health Service Management,2009(2).

[5] Van Doorslaer,E.,Wagsraff,A.,Bleichrodt,H.et al. Income-related inequalities in health: Some international comparisons[J], Joumal of Health Econonmics, 1997,16:93-112.

[6]Schultz,T.P. Human Capital,Schooling and Health, IUSSP International Population Conference-Beijing[J],1997,1499-1515.

[7]Hong Wang,Winnie Yip,Licheng Zhang,William C. Hsiao.The Impact Of Rural Mutual Health Careon Health Status:Evauation Of A Social Experiment In Rural China,Health Economics Health Econ,2009, 18:S65-S82. 